\title{
Estimating Diversity Effects in the Neighborhood: On the Role of Ethnic Diversity and Out-group Size and their Associations with Neighborhood Cohesion and Fear of Crime
}

\author{
Iris Glas ${ }^{1}$ (D) $\cdot$ Roel Jennissen ${ }^{2} \cdot$ Godfried Engbersen $^{1}$
}

Accepted: 26 April 2021 / Published online: 4 May 2021

(c) The Author(s) 2021

\begin{abstract}
This study considers and simultaneously tests the role of ethnic diversity and out-group size in relation to individuals' perceptions of neighborhood cohesion and fear of crime among natives in Dutch neighborhoods. We challenge the way the impact of diversity has been studied previously and propose an alternative measure to examine diversity effects. This results in a better understanding of how and why the ethnic composition of a neighborhood may impact levels of cohesion and fear, and thereby contributes to the literature on the societal effects of ethnic diversity. In addition, attention is paid to the association between cohesion and fear and whether neighborhood cohesion mediates the relationship between ethnic diversity and fear of crime. We apply multilevel equation modeling techniques to analyze the different relationships and use data of the Dutch Safety Monitor $(N=71,760)$ in combination with detailed register data. Our study is one of the first to detect a diversity effect on cohesion based on the modified diversity measure. We do not find support for the hypothesized diversity effect on fear of crime. Lastly, out-group size turned out to decrease cohesion and increase fear.
\end{abstract}

Keywords Ethnic diversity $\cdot$ Neighborhood cohesion $\cdot$ Fear of crime $\cdot$ Out-group size

\section{Introduction}

Contemporary societies are becoming increasingly ethnically diverse. Diversity levels are likely to continue to increase as migration continues. Researchers have also observed that migration flows have become highly diverse with migrants originating from an increasingly diverse array of countries (Castles et al., 2014; Vertovec, 2007). The societal consequences of these rising diversity levels have become the topic of heated debate. Scholars and policymakers have directed their attention in particular to the question of whether and

Iris Glas

glas@essb.eur.nl

1 Department of Public Administration and Sociology, Erasmus University Rotterdam, Mandeville Building, P.O Box 1738, 3000 DR Rotterdam, The Netherlands

2 The Netherlands Scientific Council for Government Policy, The Hague, The Netherlands 
how diversity complicates social relationships. Putnam's (2007) study on the eroding effect of diversity on social cohesion has been especially influential in this regard. Empirical evidence suggests that ethnic diversity is mainly associated with decreasing levels of intraneighborhood cohesion. ${ }^{1}$ Criminologists have also examined the role of ethnic diversity in local communities. Here, diversity is considered a relevant predictor of fear of crime. Research demonstrates that greater ethnic diversity in the residential context is associated with higher fear levels (Brunton-Smith \& Sturgis, 2011; Covington \& Taylor, 1991; Hooghe \& De Vroome, 2016; Liu \& Polson, 2016).

Our study challenges the ways in which ethnic diversity has been generally understood and measured in most previous research. We argue that commonly-used measures insufficiently reflect the enormous diversity of modern societies and propose a modified and refined operationalization of diversity, which involves an adapted version of the classical Herfindal-Hirschman-Index (HHI). The HHI is a widely used diversity index to measure ethnic heterogeneity in neighborhoods. ${ }^{2}$ Our modified HHI measure is group-specific and assesses the level of diversity among members of the out-group (i.e. the group an individual does not belong to) from the perspective of the in-group (i.e. the group an individual does belong to). This approach differs from how scholars are currently using the HHI, where all habitants from the same neighborhood receive an identical diversity score, regardless of their ethnicity. The current study follows up on Koopmans and Schaeffer (2015) who introduced a similar innovation to test diversity effects on neighborhood cohesion among German respondents $(N=7500)$. We use the modified, group-specific HHI to estimate diversity effects on individuals' perceptions of neighborhood cohesion of and fear of crime, relying on large-scale survey data from the Dutch Safety Monitor $2014(N=71,760)$ combined with individual-level register data from Statistics Netherlands. From this point forward, we refer to individuals' perceptions of neighborhood cohesion also as 'neighborhood cohesion'; the same holds for individuals' perceptions of fear of crime, which we will refer to as 'fear of crime'. We estimate diversity effects on neighborhood cohesion and fear from the perspective of Dutch natives, mainly for practical reasons. ${ }^{3}$ Consequently, non-native Dutch are considered the out-group in this study and native Dutch the in-group. One of the main aims of the current research is to improve our understanding of the social implications of living in diversity.

Not only do we consider the effect of diversity on patterns of cohesion and fear, but we also examine the role of out-group size. Taken together, this approach allows for a more adequate analysis of the mechanisms that help to explain why and how a neighborhood's ethnic composition affects cohesion and fear levels. We identify two mechanisms (Van der Meer \& Tolsma, 2014). The first mechanism considers how diversity causes feelings of anomie, which ultimately result in social isolation and fear. The second mechanism is informed by conflict theory, and specifies that a large out-group induces feelings of threat which negatively affect cohesion and perceived safety. Most previous studies are unable to differentiate between these two mechanisms as existing measures of diversity and

\footnotetext{
1 Support for negative diversity effects is most frequently found in relation to indicators of cohesion that are spatially bound to the neighborhood. Other aspects of cohesion, such as generalized trust or citizen participation, seem to be largely unaffected by diversity (Lancee and Dronkers 2011; Laurence et al. 2019; Tolsma et al. 2009).

${ }^{2}$ Note that researchers almost always use the inverse of the HHI: 1 minus the HHI. In this version of the HHI, a higher score indicates a higher level of diversity. We also use the HHI in this way.

${ }^{3}$ Unfortunately, our sample is too small to test our hypotheses separately for other ethnic groups.
} 
out-group size appear to be highly collinear (Koopmans \& Schaeffer, 2016; Laurence et al., 2019; Schaeffer, 2013; Uslaner, 2011). In the current study, we distinguish between diversity and out-group size (both conceptually and empirically).

We also examine potential interrelationships between fear of crime and neighborhood cohesion, and aim to explore to what extent neighborhood cohesion mediates the relationship between ethnic diversity and fear of crime. Theoretically, there are two opposing views on how neighborhood cohesion and feelings of unsafety may relate to each other: attachment in the neighborhood is expected to either reinforce or weaken feelings of safety (Boessen et al., 2017; Kanan \& Pruitt, 2002; Yuan \& McNeeley, 2016). The empirical evidence is somewhat mixed, although most studies have found a negative relationship between cohesion and fear (Franklin et al. 2008). These associations are most often empirically tested at the individual level (e.g. Adams \& Serpe, 2000; Drakulich, 2015; Gibson et al., 2002, see for an exception Yuan \& McNeeley, 2015). Our research design, however, makes it possible to assess the relationship between fear and cohesion at both the individual level and the neighborhood level.

Overall, this paper contributes to the literature in the following ways. First, by using an alternative measure to study diversity effects on fear of crime and neighborhood cohesion and second, by examining whether the relationship between diversity and fear of crime is mediated by neighborhood cohesion. We apply multilevel equation modeling techniques to study the relationships and to test the potential mediation effect. The main research questions we aim to answer are:

1 To what extent does ethnic diversity in the neighborhood relate to neighborhood cohesion and fear of crime?

2 Is the association between ethnic diversity and fear of crime mediated by neighborhood cohesion?

This article proceeds as follows. Firstly, we elaborate on the role of ethnic diversity (versus out-group size) and why diversity in a neighborhood may impact levels of cohesion and fear. Secondly, we look more closely at how to measure diversity. Next, we consider the relationship between fear and cohesion. We then describe the data and our modeling strategy in more detail, before presenting the results of the statistical analyses. We conclude with a discussion of the results and their implications, and address the study's limitations.

\section{Theoretical Framework}

The current paper distinguishes two dimensions of ethnic composition: ethnic diversity and out-group size (i.e. the share of the group a person does not belong to). Diversity refers more specifically to the distribution of inhabitants among different groups. The level of diversity is determined by two conditions: the number of groups present and the relative size of each group. A neighborhood is highly diverse if there is a large variety of groups and if the population is evenly distributed across these groups (Blau, 1977, p. 77-78).

\subsection{Empirical Findings Linking Ethnic Composition to Cohesion and Fear of Crime}

A lot of studies have empirically tested the relationship between ethnic composition and social cohesion. Scholars have looked at the impact of diversity on generalized trust (e.g. 
Hooghe et al., 2009), citizen participation (e.g. Gijsberts et al., 2012) and intra-neighborhood cohesion (e.g. Bécares et al., 2011). In most studies, these relationships were examined within the residential context of neighborhoods. More recently, researchers have also considered other contexts such as the workplace (Laurence et al., 2018). Van der Meer and Tolsma's (2014) meta-analysis demonstrated that ethnic diversity in the residential environment is most consistently associated with decreases in intra-neighborhood cohesion. Unfortunately, these results tell us little about diversity effects per se because of the previously mentioned entanglement of diversity and out-group measures (Koopmans \& Schaeffer, 2016; Schaeffer, 2013; Tolsma \& Van der Meer, 2017; Uslaner, 2011).

As for fear of crime, most empirical research has been conducted within the context of American neighborhoods. Those studies are primarily restricted to examining the effect of minority concentration on feelings of safety and have repeatedly shown that the presence of African American residents is related to more fear, in particular amongst white Americans (Chiricos et al., 1997; Moeller, 1989; Pickett et al., 2012). This relationship is possibly caused by stereotypes depicting African Americans as being prone to crime and violence (Eitle \& Taylor, 2008). Research examining contextual effects of ethnic composition on feelings of unsafety outside the United States is rather limited (for exceptions see BruntonSmith \& Sturgis, 2011; Glas et al., 2019; Hooghe \& De Vroome, 2016). In the next section, we will discuss the mechanisms that help explain why we expect that diversity and outgroup size have an impact on fear and cohesion.

\subsection{Mechanisms Linking Ethnic Composition to Cohesion and Fear of Crime}

Scholars examining diversity effects generally do so on the basis of the constrict hypothesis (Putnam, 2007) or the sub-cultural diversity hypothesis (Merry, 1981). The former hypothesis relates greater diversity to decreasing levels of social cohesion, while the latter predicts a positive relationship between diversity and fear. Both propose that diversity complicates social relationships, because shared values and a shared language are less likely to be present in a diverse setting. Inhabitants of these settings may therefore feel they lack knowledge of how to socially interact with each other (Van der Meer \& Tolsma, 2014). Feelings of anomie and uncertainty emerge, causing inhabitants to avoid interaction and socially isolate themselves. Fear-of-crime scholars emphasize that people living in diverse settings find it more difficult to interpret each other's behaviors and manners, which makes the presence of other ethnic groups "fear-inspiring" (Covington \& Taylor, 1991, p. 232). This argument centers on the difference between one's own ethnicity and that of one's surrounding neighbors and does not link ethnicity to fear per se (Bennett \& Flavin, 1994; Liu \& Polson, 2016; Merry, 1981).

Based on conflict and threat theory, scholars have pointed out how increases in outgroup size may spur competition between ethnic groups for scarce resources such as jobs and housing, and non-material resources, such as morality and identity (Van der Meer \& Tolsma, 2014). Out-group size is thus considered a crucial indicator of inter-group competition (Schlueter \& Scheepers, 2010). Processes of competition improve in-group solidarity, but at the same time increase out-group distrust and prejudice (Blalock, 1967; Quillian, 1995). Inhabitants who feel threatened interact less with their out-group neighbors and experience more fear. The extent to which an individual perceives an out-group as threatening, may depend on his or her own socio-economic status (Laurence et al. 2019). Studies show that in particular the native majority feels unsafe when more ethnic minorities are present (Hooghe \& De Vroome, 2016; Pickett et al., 2012). This line of research 
distinguishes between members belonging to the 'dominant' majority and those belonging to 'subordinate' minority groups, and how the presence of the latter causes feelings of threat among majority group members (Quillian, 1995). These feelings easily result in prejudice and stereotyping and may, in turn, negatively affect perceptions of neighborhood safety and cohesion (Pickett et al. 2012; Quillian \& Pager, 2001).

\subsection{Measuring and Testing the Role of Ethnic Diversity}

This section looks more closely at the measurement of ethnic diversity (for a more elaborate discussion of population diversity see Lieberson, 1969). The HHI is a commonly used diversity index. The same underlying formula is used to measure ethnic fractionalization within countries (Kolo, 2012). The height of the HHI depends on (1) the number of ethnic groups present in a neighborhood and (2) their relative size. The HHI score increases when a neighborhood's population is composed of a relatively large number of groups that are equal in size. ${ }^{4}$ In the current paper, we calculate diversity levels based on an adjusted version of the HHI. This version is group-specific and assesses diversity among members of the out-group in each neighborhood. Those living in the same neighborhood and sharing the same ethnicity obtain a similar score. This differs from the traditional HHI where all habitants from the same neighborhood receive an identical score, regardless of their ethnicity.

The formulas of the traditional HHI and group-specific HHI are largely comparable:

$$
\begin{gathered}
\text { traditional } \mathrm{HHI}=1-\sum_{i=1}^{N} s_{i}^{2} \\
\text { group - specific HHI }=1-\sum_{j=1}^{G} s_{j}^{2}
\end{gathered}
$$

In the traditional formula, $s_{i}$ is the share of ethnic group $\mathrm{i}$ (of the total population) and $\mathrm{N}$ stands for the total number of groups. For the group-specific formula, $s_{j}$ denotes the share of out-group $\mathrm{j}$ (of the out-group population) and $\mathrm{G}$ the number of out-groups.

For both versions of the HHI, the researcher decides how many groups are distinguished and included in the calculations. Most Dutch scholars calculate the HHI based on a distinction of seven groups or less (Gijsberts et al., 2012; Lancee \& Dronkers, 2011; Tolsma et al., 2009; Vervoort et al., 2011). ${ }^{5}$ We argue that a HHI based on only seven groups fails to capture the "enormous diversity of ethnic groups" present in European cities (Crul, 2016, p. 57), resulting in underestimated diversity levels. In contrast, Koopmans and Schaeffer (2015), who study group-specific diversity effects on neighborhood cohesion, do not use any clustering and include every ethnic group separately. Here, the level of diversity may

\footnotetext{
${ }^{4}$ For instance, when a neighborhood consists of four groups that are equal in size, the HHI is 0.75 ; when a neighborhood consists of one relatively large group (making up $60 \%$ of the population) and three smaller groups that are equal in size the HHI decreases to 0.59. It is an increasing function of the number of groups. It is therefore different than measures of polarization such as the Reynal-Querol-Index (2002) which reaches its maximum with two equally sized groups and decreases afterwards (Kolo 2012, p.5).

5 These researchers distinguish between inhabitants from a Turkish, Moroccan, Surinamese, Antillean, other non-Western, Western and Dutch background.
} 
(a)

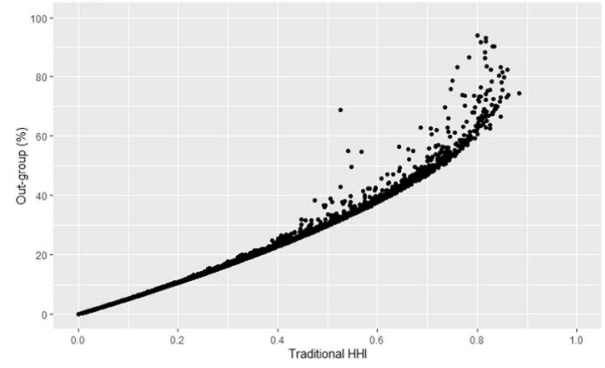

(b)

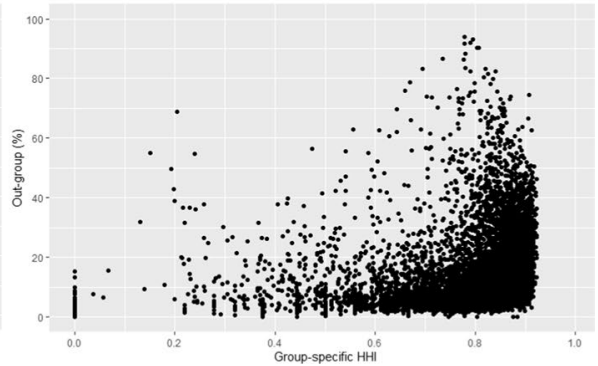

Fig. 1 Measuring ethnic composition for Dutch natives. The dots represent all neighborhoods included in the study a Out-group size and the traditional HHI b Out-group size and the group-specific HHI

be overestimated. In the current study, we distinguish between 18 groups to do justice to the diversity within Dutch neighborhoods. ${ }^{6}$ The categorization is a geo-linguistic classification, predominantly based on language and religion and refined with information on the political system of the country of origin (Jennissen et al., 2018). ${ }^{7}$

The group-specific HHI is preferred over the 'traditional' HHI for two reasons. First, it makes it possible to test the effects of diversity and out-group size simultaneously because correlations between the two measures are reduced. Secondly, the adjusted HHI is a less ambiguous diversity measure. Most existing diversity indices implicitly assume that all inhabitants experience 'diversity' in their neighborhood in a similar way. This is, however, unlikely: for native inhabitants, living in an area with high diversity means living amongst fewer co-ethnics. For non-natives, the reverse tends to be true (Abascal \& Baldassarri, 2015; Schaeffer, 2013). We observe these patterns as well in Dutch neighborhoods. ${ }^{8}$ Because people are more likely to interact with similar others (i.e. members of their ingroup), native Dutch living in relatively homogeneous neighborhoods are more likely to have contacts with other natives than those living in diverse neighborhoods (McPherson et al., 2001). The opposite is the case for non-natives residing in a diverse neighborhood. It follows that we cannot conclude whether a possible diversity effect-when measured by the traditional HHI-is the result of actual diversity or of living with fewer co-ethnics. The group-specific HHI, in sum, enables us to better locate diversity effects since the share of the in-group and hence the role of in-group contact is left out. The group-specific diversity measure ensures that the effect of diversity is now disentangled from the effect of not living with co-ethnics.

To better illustrate how out-group size, the group-specific HHI and the traditional HHI relate, we visualize their relationships in the scatterplots below (Fig. 1). The measures were calculated for Dutch natives as they are the focus of the current study. It follows that,

\footnotetext{
6 To illustrate: the average group-specific diversity level for natives based on five groups is 0.45 ; based on 17 groups the average diversity level is 0.74 .

7 We distinguish between people from Anglo-Saxon countries; German-speaking countries; Scandinavian countries; Mediterranean countries; Middle and Eastern Europe; Arab countries; Latin America; Sub-Saharan Africa; South Asia; Central Asia; South-East Asia and the Pacific; East Asia; former Dutch colonies (Surinam and the former Netherlands Antilles); Belgium; Indonesia; Morocco; the Netherlands and Turkey.

${ }^{8}$ In an average homogenous neighborhood, approximately 90 percent of the residents are native Dutch. This percentage drops to 72 percent for an average heterogeneous neighborhood. Diversity scores are calculated based on the traditional HHI. The median heterogeneity score is 0.27 .
} 
in the current research, the out-group consists of all non-native Dutch inhabitants. Whether a group belongs to the out-group depends on which is group is chosen as the in-group. The points in the scatterplots of Fig. 1 represent the neighborhoods included in the current study. The left plot (Fig. 1a) shows that there is little distinction between out-group size and the traditional $\mathrm{HHI}$, indicating that these variables are empirically almost entirely similar (see also Gijsberts et al., 2012, p. 536). This is confirmed by the high correlation coefficient $(r=0.98)$. The right plot (Fig. 1b), based on the group-specific HHI, shows a much more dispersed pattern; out-group size and diversity are now two empirically distinct dimensions of ethnic composition. The measures are only weakly correlated $(r=0.24)$. Figure $1 \mathrm{~b}$ further suggests that there is a relatively large share of neighborhoods with a small out-group that is highly diverse. Approximately one-fourth of the neighborhoods fall into this category (compared to zero when diversity is measured in the traditional way). ${ }^{9}$ This is not necessarily surprising because the share of native Dutch-which would bring down a neighborhood's diversity level when included-is no longer part of how the diversity score is calculated. The specific characteristics raise the question of whether the hypothesized diversity effects operate similarly or differently depending on out-group size. We examine this option more closely in the statistical analyses.

\subsection{An (Mediating) Effect of Neighborhood Cohesion on Fear of Crime}

In this last theoretical section, we further elaborate on the potential dependency between cohesion and fear, and on whether perceptions of cohesion mediate the relationship between ethnic diversity and fear. We focus on individuals' perceptions of fear and cohesion and how these perceptions vary within and between neighborhoods. Note that the hypothesized mediation can only occur at the neighborhood level (i.e. between level) since ethnic diversity is a contextual characteristic that does not vary within neighborhoods. It follows that diversity levels cannot account for individual (i.e. within) differences in cohesion and fear (Laméris et al., 2018; Preacher et al., 2010). The potential mediating role of cohesion will thus be modeled and assessed at the between (or: neighborhood) level. At the within level, we only consider the association between cohesion and fear. We analyze the different levels and pathways within the framework of multilevel structural equation modeling (MSEM) (Preacher et al., 2010). Further details can be found in Sect. 3.5 (analytical strategy). The main model is illustrated in Fig. 2

The mediating role of cohesion has already been well documented in studies aimed at understanding neighborhood crime patterns. Based on collective efficacy theory, scholars found that the relationship between certain neighborhood characteristics (including ethnic composition) and violent crime is largely mediated by the aggregated level of cohesion and informal social control in a neighborhood (Morenoff et al., 2001; Sampson et al., 1997). This line of research suggests that inhabitants living in cohesive neighborhoods are more likely to use informal means to control their neighborhood with the aim of reducing problems related to crime and disorder. The presence of these social informal controls in a neighborhood may result (both directly and indirectly) in increased feelings of safety (Scarborough et al., 2010). Based on this literature, we expect that cohesion (at least) partially mediates the hypothesized relationship between diversity and fear. The empirical evidence on the association between cohesion and fear is, however, rather limited and mixed.

\footnotetext{
${ }^{9}$ In these neighborhoods, the out-group is smaller than $10 \%$ and the HHI is larger than 0.8 .
} 


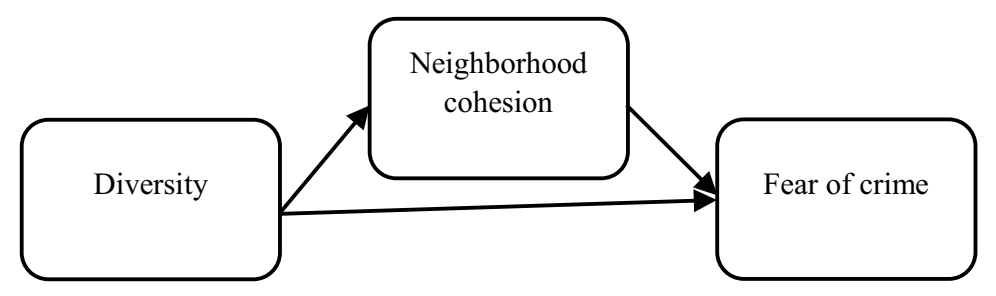

Between: neighborhood level

Within: individual level

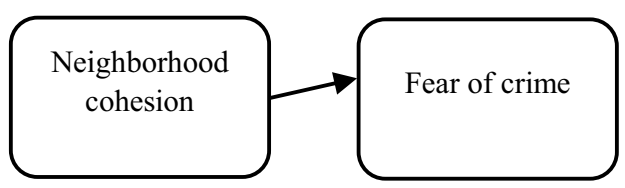

Fig. 2 Main conceptual model

A study by Yuan and McNeeley (2015) demonstrated that the strength of social networks in a neighborhood was not associated with inhabitants' perceived risk or worries about victimization. Rountree and Land (1996) showed that social integration (at the neighborhood level) diminishes residents' perceptions of the neighborhood as being unsafe, but simultaneously results in higher levels of burglary-specific fear.

At the individual level, there are at least three pathways that link cohesion to fear. The first two hypothesize that cohesion and feelings of safety are positively related. Cohesion contributes to more safety either by providing inhabitants with a greater sense of familiarity or by providing them with better access to support resources (Boessen et al., 2017). Being familiar with the neighborhood and the inhabitants makes it easier to 'place' each other in public space, which in turn contributes to an improved sense of safety (Blokland, 2017). Besides, neighborhood ties may function as potential resources for support on which residents can rely if necessary. Inhabitants who feel more supported will experience less vulnerability and, consequently, less fear (Boessen et al., 2017; Kanan \& Pruitt, 2002). The positive relationship between neighborhood cohesion and feelings of safety is supported by various studies. It has been shown that residents who feel more attached to the neighborhood report lower levels of fear of crime (Adams \& Serpe, 2000; Riger et al., 1981). Yuan and McNeeley (2015) found that people are less likely to consider their neighborhood as being unsafe when they have more friends or family living nearby.

Scholars have also hypothesized that cohesion may harm feelings of safety. In this case, neighborhood ties are expected to increase fear levels because residents with more ties are more likely to be exposed to crime-related news and information. It is predicted that increased exposure enhances the effect of indirect victimization and causes more concern about crime in the neighborhood, resulting in higher levels of fear (Covington \& Taylor, 1991; Yuan \& McNeeley, 2015). Other researchers have argued that the relationship between social ties and fear may be reciprocal, implicating that diminished social ties are both a cause and a consequence of fear (Kanan \& Pruitt, 2002; Liska et al. 1988). We cannot empirically rule out the reverse causality because our paper relies on cross-sectional data. 


\subsection{Hypotheses}

Based on the literature outlined above, we formulate the following four hypotheses:

Hypothesis 1: Residents living in neighborhoods with more diversity experience more fear of crime.

Hypothesis 2: Residents living in neighborhoods with more diversity experience less neighborhood cohesion (2a), which in turn increases fear of crime (2b).

Hypothesis 3: Residents living in neighborhood with a larger out-group experience more fear of crime (3a) and less neighborhood cohesion (3b).

Hypothesis 4: Residents who report higher levels of neighborhood cohesion experience less fear of crime.

All hypotheses are tested at the between level, with the exception of the fourth hypothesis which is examined at the within level.

\section{Research Design}

\subsection{Data}

The current study uses data from the Dutch Safety Monitor 2014 and individual register data from Statistics Netherlands. The Safety Monitor is a nationwide survey on crimerelated feelings of unsafety and victimization. It is a high-quality national survey with a large and representative sample. Respondents were sampled from the municipality population register. The size of the sample was large enough to ensure that the respondents are equally distributed across the entire country. The overall response rate was $38.8 \%$. In total, 86,382 respondents completed the self-administered questionnaires, either online $(47.9 \%)$ or through a written questionnaire $(52.1 \%) .{ }^{10}$ The respondents live across the entire Netherlands, in areas with varying levels of ethnic diversity. Only the native Dutch respondents $(N=71,760)$ were selected for this study. ${ }^{11}$ Unfortunately, our sample is too small to test our hypotheses separately for other ethnic groups. On average, approximately 8.3 native respondents share the same neighborhood. This is sufficient to correctly estimate regression coefficients and variance components, as well as the corresponding standard errors (Maas \& Hox, 2005). The selected respondents live across the entire Netherlands and reside in 8,621 neighborhoods; $72 \%$ of all Dutch neighborhoods are included in the survey. The neighborhoods are administratively defined and have an average population size of 1,400 inhabitants. We merged the survey data with non-public individual register data ('microdata') from Statistics Netherlands. Access to microdata was granted under specific

\footnotetext{
10 Statistics Netherlands (2015). Veiligheidsmonitor 2014. Retrieved from http://download.cbs.nl/pdf/veili gheidsmonitor-2014.pdf (accessed September 23, 2019).

11 A person is considered native if both parents were born in the Netherlands.
} 
Table 1 Descriptive statistics neighborhood-level variables

\begin{tabular}{lcccr}
\hline & Min & Max & Mean & \multicolumn{1}{c}{ SD } \\
\hline HHI & 0 & 0.92 & 0.84 & 0.10 \\
Out-group & 0 & 94.05 & 19.95 & 15.49 \\
Economic disadvantage & -4.5 & 5.63 & -0.08 & 0.75 \\
Burglary & 0 & 225 & 5.22 & 4.31 \\
Violent crime & 0 & 615 & 5.38 & 9.10 \\
\hline
\end{tabular}

conditions. ${ }^{12}$ We used data on the ethnicity of all Dutch inhabitants and information on the economic situation of all Dutch households.

\subsection{Neighborhood cohesion and fear of crime}

In our analysis, two outcome variables are distinguished: perceptions of neighborhood cohesion and fear of crime. The former is measured through a set of four items. These items are people in this neighborhood socialize pleasantly; I live in a cozy neighborhood where people help each other out and do things together; I feel at home with the people living in this neighborhood; and I have a lot of contact with other neighbors (answer categories: agree completely, agree, neither agree nor disagree, disagree and disagree completely). A factor analysis indicated that all four items load onto a single factor (see Table 5 in Appendix for details). The four items also appear to form a unidimensional scale, accounting for $71.10 \%$ of the variance. The scale is based on the average of at least three valid answers and is internally consistent with a Cronbach's $\alpha$ of 0.86 . This measure of neighborhood cohesion will be used to model cohesion both at the individual level and the neighborhood level.

To measure of fear of crime, three sub-dimensions are combined that relate to elements of behavior, threat and risk (Skogan, 1999). We constructed a scale consisting of five items. Respondents were asked how often they do not answer the door during evening hours; avoid certain areas in their neighborhood; feel unsafe walking in their neighborhood or being home alone during the evening; and are afraid of being victimized (answer categories: seldom or never, occasionally and frequently). A factor analysis resulted in one single factor (see Table 6 in Appendix for details). The items also proved to form a unidimensional and internally coherent scale, explaining $52.91 \%$ of the variance with a Cronbach's $\alpha$ of 0.85 . The fear of crime scale represents the average of at least three valid answers. A higher score on the scale indicates more fear of crime.

\subsection{Ethnic Diversity and the Out-Group}

The diversity measure is based on the distribution of out-group members among (a maximum of) 17 groups. Because only native Dutch were included in the analysis, the out-group consists of inhabitants with a migration background (or, in other words, non-native Dutch).

\footnotetext{
12 Statistics Netherlands (2017). Catalogue of services Microdata services 2018. Retrieved from https://www.cbs.nl/-/media/_pdf/2017/48/171201\%20services\%20catalogue\%202018.pdf (accessed September 23, 2019).
} 
Table 2 Results path analysis

\begin{tabular}{llc}
\hline & $\begin{array}{l}\text { Cohesion } \\
\text { B SE }\end{array}$ & $\begin{array}{l}\text { Fear of crime } \\
\text { B SE }\end{array}$ \\
\hline Between level & & $-0.204(0.037)^{* * * *}$ \\
Cohesion & & $-0.105(0.023)^{* * *}$ \\
HHI & $-0.389(0.029)^{* * *}$ & $0.003(0.000)^{* * *}$ \\
Out-group & $-0.006(0.000)^{* * *}$ & $0.003(0.000)^{* * *}$ \\
Burglary & & $0.001(0.000)^{* * *}$ \\
Violent crime & & $-0.004(0.004)$ \\
Economic disadvantage & $-0.040(0.005)^{* * * *}$ & \\
Within level & & $0.006(0.002)^{* *}$ \\
Cohesion & & \\
$N$ & 66,101 & \\
\hline
\end{tabular}

Individual-level control variables are not shown

$* p<0.05, * * p<0.01, * * * p<0.001$

The out-group variable is calculated as the number of 'out-group' inhabitants divided by the total number of inhabitants. The diversity measure and out-group variable are based on the ethnic composition of neighborhoods in 2014.

\subsection{Control Variables}

We control for several variables at the neighborhood level and individual level. Previous research has identified these controls as relevant determinants of neighborhood cohesion and/or fear of crime. At the neighborhood level, measures of economic disadvantage and crime are included. To measure the degree of economic disadvantage, an index was constructed that combines the percentage of low-income households, the average income of the context and the percentage of households for which social security is the main source of income (e.g. Vervoort, 2012). Before constructing the index, the distribution of average income was reversed and all indicators were standardized. Lastly, the mean of the standardized indicators was calculated. To control for crime, we included the registered number of reported burglaries and the registered number of violent crime incidents. ${ }^{13}$ These variables represent the incidence of either burglary or violent crimes per 1000 members of the population in 2014 in a neighborhood. The descriptive statistics for the neighborhood-level variables (all measured continuously) are presented in Table 1.

The individual control variables are age (in decades), gender, education level, presence of children in the household, whether social benefits are the main source of income of the household, income level and length of residence in the neighborhood (in years). When analyzing fear, we also controlled for burglary victimization. This variable is self-reported and was measured by asking respondents whether they had been a victim of burglary during the past five years. The descriptives (minimum and maximum values, mean, standard deviation

\footnotetext{
13 Statistics Netherlands (2016). Geregistreerde criminaliteit per gemeente, wijk en buurt, 2010-2015. Retrieved from https://www.cbs.nl/-/media/_excel/2016/45/geregistreerde-criminaliteit-per-gemeente-wijken-buurt-2010-2015.xlsx (accessed September 23, 2019).
} 


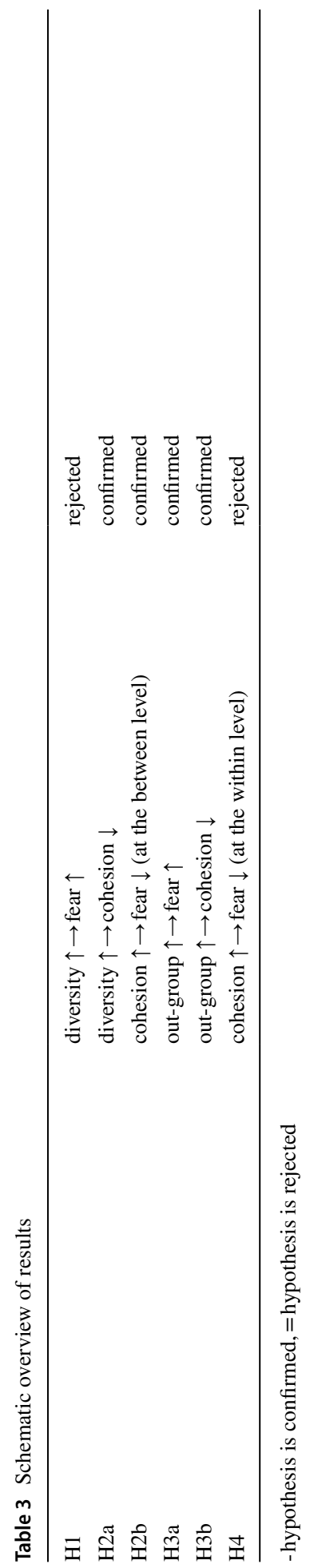

Springer 
Table 4 Results path analysis. (Non-)European/Anglo-Saxon diversity and out-groups

\begin{tabular}{llc}
\hline & $\begin{array}{l}\text { Cohesion } \\
\text { B SE }\end{array}$ & \multicolumn{1}{l}{$\begin{array}{l}\text { Fear of crime } \\
\text { B SE }\end{array}$} \\
\hline Between-level & & $-0.213(0.035)^{* * *}$ \\
Cohesion & & $-0.091(0.015)^{* * *}$ \\
HHI European/Anglo-Saxon & $-0.301(0.035)^{* * *}$ & $-0.031(0.009)^{* *}$ \\
HHI non-European/Anglo-Saxon & $-0.118(0.021)^{* * *}$ & $0.002(0.000)^{* * *}$ \\
Out-group European/Anglo-Saxon & $-0.009(0.001)^{* * *}$ & $0.003(0.000)^{* *}$ \\
Out-group non-European/Anglo-Saxon & $-0.009(0.000)^{* * *}$ & $0.003(0.000)^{* * *}$ \\
Burglary & & $0.001(0.000)^{* * *}$ \\
Violent crime & & $-0.041(0.005)^{* * *}$ \\
Economic disadvantage & $-0.045(0.005)^{* * *}$ & \\
Within level & & $0.006(0.003)^{* * *}$ \\
Cohesion & & \\
$N$ & 66,101 & \\
\hline
\end{tabular}

Individual-level control variables are not displayed

${ }^{*} p<0.05, * * p<0.01, * * * p<0.001$

and measurement scale) for the individual-level variables are included in Table 7 in the Appendix.

\subsection{Analytical Strategy}

We applied multilevel structural equation modeling (MSEM) to test the proposed pathways. MSEM is considered the most appropriate method to examine mediation in nested data because it explicitly separates the between level (neighborhoods) from the within level (individuals). ${ }^{14}$ We follow the approach introduced by Preacher and colleagues (2010; 2011) to test mediation in a 2-1-1 design, with neighborhood diversity as a level 2 characteristic and cohesion and fear as level 1 characteristics. As mentioned previously, the mediation is examined at level 2 (the neighborhood level) because diversity is a neighborhoodlevel variable (for an illustration see Laméris et al., 2018). Based on the null model, we calculated intraclass correlations (ICCs) for an indication of how much variance is located at the neighborhood level. The ICCs vary between 0.07 (fear) and 0.09 (cohesion). These ICC values indicate that only a low proportion of the variance can be attributed to the neighborhood level. We obtained Akaike information criterion (AIC) and Bayesian information criterion (BIC) values to compare the model fit between the null model, the model with individual-levels variables and the 'full' model with both individual and neighborhood-level variables. ${ }^{15}$ AIC and BIC are both criteria methods for model selection and to assess model fit. Lower values indicate a better model fit. Our full model proved to have the best model fit. We specify random intercepts and fixed slopes and perform our analyses

\footnotetext{
${ }^{14}$ MSEM is a different approach than previous methods testing mediation within a two level framework (which include two-step analyses and aggregation). In these previous methods, group means of a Level 1 variable are used at Level 2 to represent group standings on a Level 1 variable. In MSEM, group standings on a Level 1 variable are treated as latent. For a more elaborate discussion of these different approaches see Preacher et al. 2010.

${ }^{15}$ Other goodness-of-fit statistics are not yet available in R.
} 
in R, using the lavaan package (version 0.6-4). The random intercepts allow that the (individual) scores for fear of crime and neighborhood cohesion are predicated by the level of ethnic diversity which varies between neighborhoods. The slopes are fixed, meaning that it is assumed that the size of the potential diversity effect is the same for every individual (regardless of the neighborhood).

\section{Results}

\subsection{Results from the Main Model}

The results of our main model are shown in Table 2. All control variables are included. Most effects of the individual-level controls are in line with previous research (see Table 8 in the Appendix for details). This is also the case for the results regarding the neighborhood-level control variables. We find that in economically disadvantaged neighborhoods, cohesion levels are lower $(b=-0.040)$ on average. There is, however, no significant association between economic neighborhood status and reported fear. In addition, it is shown that higher burglary rates and a higher incidence of violent crimes are significantly associated with more fear in the neighborhood ( $b=0.003$ and $b=0.001$, respectively).

Next, we considered the diversity effects more closely. We observed that the diversity effect on fear of crime is not in line with our expectations: surprisingly, a higher level of diversity in the neighborhood is related to less fear. More specifically, inhabitants experience $0.01(b=-0.105 \times 0.10)$ less fear if diversity increases by $10 \%$ points. A possible explanation is that in highly diverse neighborhoods the out-group is more fragmented and, as a result, there is less threat because there is no dominant majority. The observed diversity effect-assessed at a 3-point scale-is, however, relatively small. The societal significance of this finding should therefore not be overestimated (Bernardi et al. 2017). Moreover, in an additional robustness analysis the diversity effect on fear was no longer significant. ${ }^{16}$ It follows that hypothesis 1 , predicting more fear in more diverse neighborhoods, is rejected.

The model also shows that more diversity in the neighborhood is related to less neighborhood cohesion. This diversity effect is in line with Putnam's constrict hypothesis (2007) and most previous research on this relationship (e.g. Gijsberts et al., 2012; Lancee \& Dronkers, 2011). In a neighborhood with $10 \%$ points more diversity, the average level of cohesion decreased by $0.04(b=-0.389 \times 0.10)$, measured on a 5 -point scale. Hypothesis 2a-more diversity is associated with less neighborhood cohesion-is thus confirmed. ${ }^{17}$ It was found that, at the between-level, higher levels of cohesion are accompanied by less fear $(b=-0.204)$. This result supports hypothesis $2 \mathrm{~b}$. The indirect effect of diversity on fear is $0.079(b=-0.389 \times-0.204)$, indicating that inhabitants of ethnically diverse neighborhoods experience more fear because diversity has weakened their social relationships in the neighborhood. It also demonstrates that the level of perceived safety is higher in more socially cohesive neighborhoods, which is consistent with the literature on collective efficacy and the previous findings of Rountree and Land (1996).

\footnotetext{
${ }^{16}$ If we include out-group as separate out-group variables (each representing the share of one specific outgroup) the diversity effect on fear was no longer significant. These results are not presented here but are available upon request.

17 This remained unchanged in the additional robustness analysis (see footnote 16).
} 
On the basis of the third hypothesis, we expect that a larger out-group in the neighborhood is related to more fear (3a) and less cohesion (3b). The results indicate that a larger out-group is indeed associated with 0.03 more fear if the out-group increases by $10 \%$ points $(b=0.003 \times 10)$. This finding confirms previous research showing that natives feel more unsafe in neighborhoods inhabited by a relatively large out-group. Furthermore, the outgroup effect on cohesion is also in line with our expectations. If the size of the out-group increases by $10 \%$ points, the respondents experience $0.06(b=-0.006 \times 10)$ less cohesion. Consequently, hypotheses $3 \mathrm{a}$ and $3 \mathrm{~b}$ are both supported.

At the within level, we also address the association between cohesion and fear. Our fourth hypothesis predicts a negative relationship between a resident's level of cohesion and sense of unsafety. Contrary to the hypothesis, we find that more cohesion is associated with slightly higher fear levels $(b=0.006)$. This result seems to suggest that the negative aspects of being more socially integrated in a neighborhood outweigh potential positive effects. Hypothesis 4 remains unconfirmed. All our hypotheses and their results are summarized in Table 3.

\subsection{Robustness and Additional Checks}

We carried out three additional analyses to evaluate the robustness of our results and to explore whether we can further improve our understanding of the observed effects. First, we wanted to consider the possibility that the detected diversity effect on neighborhood cohesion depends on the size of the out-group. The expectation is that the effect of diversity is stronger when the share of the out-group increases. To test this, a model was estimated including interaction effects between diversity and out-group size. The interactions turned out not to be significant, suggesting that diversity effects do not depend on outgroup size. As a second robustness check, we explored whether different outcomes are produced by excluding respondents who live in a relative diverse neighborhood (with a HHI larger than 0.8 ) with only a small out-group (less than 10\%). This model, which included 52.098 respondents, was estimated to assess whether our main model was biased by the characteristics of this specific group. The diversity effects did not, however, change much. The results of these two models are available upon request.

In our third model, we examined the role of cultural distance and whether the effects of diversity and the out-group are stronger when resulting from non-European/Anglo-Saxon ('non-Western') groups (in contrast to European/Anglo-Saxon, or 'Western', groups). ${ }^{18}$ The idea is that anomie and threat are more likely to occur when the perceived cultural distance between different group members is larger. Dutch natives consider the non-European/ Anglo-Saxon group to be the most culturally distant (Schlueter \& Scheepers, 2010). The results of this additional analysis are reported in Table 4. Our ideas are not supported: we find that diversity based on the share of European/Anglo-Saxon groups even has a slightly larger effect on cohesion. Besides, it seems to make (almost) no difference whether the

\footnotetext{
18 The category of European/Anglo-Saxon includes immigrants (and their children) from Europe (except Turkey), Canada, United States, South-Africa, Indonesia and Oceania. Indonesia is regarded as 'European' because many people who are of Indonesian origin, are either descendants of Dutch colonists or Indo-Europeans born in the former colony of the Netherlands East Indies (Jennissen 2013, p. 185). The non-European/Anglo-Saxon category includes people from Turkey, Morocco, Arab countries, Asia, Latin-America, Sub-Sahara Africa, Surinam and the former Netherlands Antilles.
} 
out-group measures are based on the composition of European/Anglo-Saxon or non-European/Anglo-Saxon groups.

\section{Discussion and Conclusion}

The current study examined to what extent the ethnic composition of Dutch neighborhoods is associated with residents' perceptions of cohesion and fear. We considered the role of two different composition aspects: (1) the level of ethnic diversity and (2) the size of the out-group. Previous scholars analyzing similar relationships have often failed to specify whether it is expected that a neighborhood's ethnic composition of a neighborhood will affect perceptions due to either diversity or due to out-group size. We argue that it is necessary to empirically distinguish between these two aspects: they are theoretically distinct and relate to different explanatory mechanisms. We did so by using group-specific measures of diversity and out-group and simultaneously analyzed their impact on both cohesion and feelings of unsafety among Dutch natives. Furthermore, in an additional analysis, we distinguished between different 'sorts' of diversity and out-groups to shed more light on the role of cultural distance and similarity. No support was found for the expectation that natives' levels of cohesion and unsafety are particularly affected by the presence of more culturally distant groups, although this is often implicitly assumed by researchers.

Our results showed that the hypothesized effect of diversity is most consistently found in relation to neighborhood cohesion. We observed that more diversity in the neighborhood is related to less cohesion. Our study is one of the first to detect a diversity effect on cohesion based on this modified measure. It is possible that the found diversity effect on cohesion is slightly underestimated since the level of diversity was not calculated on the basis of the entire neighborhood population (but only on the different shares of non-native groups). In prior research, scholars have often been unable to conclude whether reduced levels of cohesion were better explained by ethnic diversity or rather the concentration of specific minority groups (e.g. Dinesen \& Sønderskov, 2015; Glas et al., 2019; Laurence et al., 2019; Sluiter et al., 2015). We add to this literature by providing empirical support for Putnam's constrict hypothesis. Despite this contribution, two limitations should be noted here: only natives were included in the analyses and, secondly, we narrowed our focus to neighborhood cohesion, whereby we did not consider other elements of cohesion that are not neighborhood specific. Another limitation of the current study that should be mentioned is the use of cross-sectional data. We therefore cannot control for selection processes or assume causality. In order to make actual causal claims, longitudinal data are necessary.

No support was found for the diversity hypothesis regarding fear of crime. This outcome contradicts the results of a recent study that found a positive association between ethnic diversity and fear at various spatial levels, including the neighborhood (Glas et al., 2019). In this earlier study, ethnic diversity was measured using the conventional HHI. In addition, no distinction was made between the different aspects of ethnic composition. These differences may explain why contradicting results were found. The current research shows that differences in fear are better explained by the size of the out-group. We therefore conclude that diversity may induce negative effects, but that these effects are limited 
to neighborhood cohesion and do not affect fear of crime. The results suggest that feelings of anomie-which explain why cohesion levels are lower in ethnically diverse neighborhoods-do not spill-over into feelings of unsafety.

Based on the threat mechanism, we also researched the role of out-group size in relation to levels of cohesion and fear. The idea that living in a neighborhood with ethnic 'others'-regardless of their internal diversity-may be threatening, gained support. We found that a larger out-group in the neighborhood is associated with less cohesion and more fear. It follows that both the level of diversity and the size of the out-group in a neighborhood are associated with lower cohesion levels. The out-group effect on fear confirms previous research showing a positive association between the presence of minority groups and fear among members of the (traditional) majority (Chiricos et al., 1997; Moeller, 1989).

This study also examines the interrelationship between neighborhood cohesion and feelings of unsafety. We found a specific pattern for each level of analysis, indicating that the relationship between cohesion and fear operates differently at different levels. At the individual level, cohesion and fear are positively related: inhabitants who experience more cohesion report slightly higher fear levels. This supports the idea that local social ties may elevate fear levels because people who are socially integrated in the neighborhood are more exposed to crime related news and stories (Boessen et al., 2017; Covington \& Taylor, 1991). Our results also demonstrate that living in a neighborhood that is considered cohesive decreases fear levels at the neighborhood level.

Overall, we showed in our analyses which elements of the ethnic composition of a neighborhood play a role in explaining patterns of fear of crime and neighborhood cohesion and, by doing so, provide a more nuanced understanding of the diversity debate. We agree with Koopmans and Schaeffer (2015) who urged scholars to move away from using conventional diversity measures in order to "move ahead" the research field (p. 173). Our study illustrates what can be gained from using a more innovative method to measure the ethnic composition of neighborhoods when researching neighborhood cohesion and fear of crime patterns.

\section{Appendix}

See Table 5, 6, 7, 8 
Table 5 Summary factor analysis neighborhood cohesion

\begin{tabular}{lc}
\hline Item & Factor loading \\
\hline People socialize pleasantly & 0.806 \\
I live in a cozy neighborhood & 0.879 \\
I feel at home & 0.873 \\
I have a lot of contact with other neighbors & 0.812 \\
Eigenvalue & 2.844 \\
\% of variance & 71.10
\end{tabular}

\begin{tabular}{lc}
\hline Item & Factor loading \\
\hline Do not answer the door during evening hours & 0.719 \\
Avoid certain areas in the neighborhood & 0.735 \\
Feel unsafe walking in the neighborhood & 0.831 \\
Feel unsafe being home alone during the evening & 0.768 \\
Afraid of being victimized & 0.753 \\
Eigenvalue & 2.905 \\
$\%$ of variance & 58.10 \\
\hline
\end{tabular}

Table 6 Summary factor analysis fear of crime

Table 7 Descriptive statistics individual-level variables

\begin{tabular}{llllll}
\hline & Min & Max & Mean & SD & Scale \\
\hline Neighborhood cohesion & 1 & 5 & 3.46 & 0.77 & Ordinal treated as continuous \\
Fear of crime & 1 & 3 & 1.25 & 0.38 & Ordinal treated as continuous \\
Age in decades & 1.5 & 10.1 & 5.21 & 1.81 & Ratio \\
Gender (ref.=male) & 0 & 1 & 0.52 & Nominal \\
Education & & & & Ordinal \\
Low (= ref.) & 0 & 1 & 0.31 & \\
Middle & 0 & 1 & 0.28 & \\
High & 0 & 1 & 0.32 & \\
Children in household (ref. = none) & 0 & 1 & 0.40 & Nominal \\
Social benefits main income source (ref. =yes) & 0 & 1 & 0.93 & Nominal \\
Income & & & & & Ordinal \\
First quintile (= ref.) & 0 & 1 & 0.10 & \\
Second quintile & 0 & 1 & 0.21 & \\
Third quintile & 0 & 1 & 0.20 & \\
Fourth quintile & 0 & 1 & 0.22 & \\
Fifth quintile & 0 & 1 & 0.24 & \\
Length of residence in the neighborhood in & 0.08 & 95.05 & 18.76 & 13.07 & Ratio \\
$\quad$ years & & & & \\
Victim of burglary (ref. = not) & 0 & 1 & 0.12 & Nominal \\
\hline
\end{tabular}


Table 8 Results path analysis

\begin{tabular}{|c|c|c|}
\hline & $\begin{array}{l}\text { Cohesion } \\
\text { B SE }\end{array}$ & $\begin{array}{l}\text { Fear of crime } \\
\text { B SE }\end{array}$ \\
\hline Age in decades & $0.037(0.001)^{* * *}$ & $-0.001(0.001)$ \\
\hline Gender $($ ref. $=$ male $)$ & $0.051(0.005)^{* * *}$ & $0.140(0.003)^{* * *}$ \\
\hline \multicolumn{3}{|l|}{ Education $($ ref. $=$ low $)$} \\
\hline Middle & $-0.029(0.006)^{* * *}$ & $-0.042(0.003)^{* * * *}$ \\
\hline High & $-0.060(0.006)^{* * *}$ & $-0.081(0.003)^{* * *}$ \\
\hline Children in household (ref. $=$ none) & $0.097(0.005)^{* * *}$ & $-0.022(0.003)^{* * *}$ \\
\hline Social benefits (ref. = yes) & $0.050(0.011)^{* * *}$ & $-0.077(0.007) * * *$ \\
\hline \multicolumn{3}{|l|}{ Income $($ ref. $=$ first quintile $)$} \\
\hline Second quintile & $0.071(0.008)^{* * *}$ & $-0.005(0.005)$ \\
\hline Third quintile & $0.065(0.008) * * *$ & $-0.037(0.005)^{* * *}$ \\
\hline Fourth quintile & $0.049(0.008)^{* * *}$ & $-0.048(0.005)^{* * *}$ \\
\hline Fifth quintile & $0.061(0.008) * * *$ & $-0.063(0.005)^{* * * *}$ \\
\hline Length of residence in neighborhood & $0.002(0.000)^{* * *}$ & $0.001(0.000)^{* * *}$ \\
\hline Victim of burglary (ref. $=$ not) & & $0.174(0.004) * * *$ \\
\hline$N$ & 66,101 & \\
\hline
\end{tabular}

Neighborhood-level control variables are not shown

${ }^{*} p<0.05 ; * * p<0.01 ; * * * p<0.001$

Open Access This article is licensed under a Creative Commons Attribution 4.0 International License, which permits use, sharing, adaptation, distribution and reproduction in any medium or format, as long as you give appropriate credit to the original author(s) and the source, provide a link to the Creative Commons licence, and indicate if changes were made. The images or other third party material in this article are included in the article's Creative Commons licence, unless indicated otherwise in a credit line to the material. If material is not included in the article's Creative Commons licence and your intended use is not permitted by statutory regulation or exceeds the permitted use, you will need to obtain permission directly from the copyright holder. To view a copy of this licence, visit http://creativecommons.org/licenses/by/4.0/.

\section{References}

Abascal, M., \& Baldassarri, D. (2015). Love thy neighbor? ethnoracial diversity and trust reexamined. American Journal of Sociology, 121(3), 722-782

Adams, R. E., \& Serpe, R. T. (2000). Social integration, fear of crime, and life satisfaction. Sociological Perspectives, 43(4), 605-629

Bécares, L., Stafford, M., Laurence, J., \& Nazroo, J. (2011). Composition, concentration and deprivation: exploring their association with social cohesion among different ethnic groups in the UK. Urban Studies, 48(13), 2771-2787

Bennett, R. R., \& Flavin, J. M. (1994). Determinants of fear of crime: the effect of cultural setting. Justice Quarterly, 11(3), 357-381

Bernardi, F., Chakhaia, L., \& Leopold, L. (2017). Sing me a song with social significance': The (mis) use of statistical significance testing in European sociological research. European Sociological Review, 33(1), $1-15$

Blalock, H. (1967). Toward a theory of minority-group relations. Wiley.

Blau, P. M. (1977). Inequality and heterogeneity. a primitive theory of social structure. The Free Press.

Blokland, T. (2017). Community as urban practice. Polity Press.

Boessen, A., Hipp, J. R., Butts, C. T., Nagle, N. N., \& Smith, E. J. (2017). Social fabric and fear of crime: considering spatial location and time of day. Social Networks, 51, 60-72 
Brunton-Smith, I., \& Sturgis, P. (2011). Do Neighborhoods generate fear of crime? an empirical test using the british crime survey. Criminology, 49(2), 331-369

Castles, S., de Haas, H., \& Miller, M. J. (2014). The age of migration. Palgrave Macmillan.

Chiricos, T., Hogan, M., \& Gertz, M. (1997). Racial Composition of neighborhood and fear of crime. Criminology, 35(1), 107-132

Covington, J., \& Taylor, R. B. (1991). Fear of crime in urban residential neighborhoods: implications of between- and within-neighborhood sources for current models. Sociological Quarterly, 32(2), 231-249

Crul, M. (2015). Super-diversity vs assimilation: how complex diversity in majority-minority cities challenges the assumptions of assimilation. Journal of Ethnic and Migration Studies, 42(1), 54-68

Dinesen, P. T., \& Sønderskov, K. M. (2015). Ethnic diversity and social trust: evidence from the microcontext. American Sociological Review, 80(3), 550-573

Drakulich, K. M. (2015). Social capital, information, and perceived safety from crime: the differential effects of reassuring social connections and vicarious victimization. Social Science Quarterly, 96(1), 176-190

Eitle, D., \& Taylor, J. (2008). Are hispanics the new "threat"? minority group threat and fear of crime in Miami-Dade county. Social Science Research, 37(4), 1102-1115

Franklin, T.W., Franklin, C. A., \& Fearn, N. E. (2008). A multilevel analysis of the vulnerability, disorder, and social integration models of fear of crime. Social Justice Research, 21, 204-227

Gibson, C. L., Zhao, J., Lovrich, N. P., \& Gaffney, M. J. (2002). Social integration, individual perceptions of collective efficacy, and fear of crime in three cities. Justice Quarterly, 19(3), 537-564

Gijsberts, M., Van Der Meer, T., \& Dagevos, J. (2012). 'Hunkering down' in multi-ethnic neighbourhoods? The effects of ethnic diversity on dimensions of social cohesion. European Sociological Review, 28, 527-537

Glas, I., Engbersen, G., \& Snel, E. (2019). The street level and beyond: The impact of ethnic diversity on neighborhood cohesion and fear of crime among Dutch natives and nonnatives. Journal of Urban Affairs, 41(6), 737-755

Hooghe, M., \& de Vroome, T. (2016). The relation between ethnic diversity and fear of crime: An analysis of police records and survey data in Belgian communities. International Journal of Intercultural Relations, 50, 66-75

Hooghe, M., Reeskens, T., Stolle, D., \& Trappers, A. (2009). Ethnic diversity and generalized trust in Europe: A cross-national multilevel study. Comparative Political Studies, 42(2), 198-223

Jennissen, R. (2013). Recorded crime committed by migrant groups and native Dutch in the Netherlands. In M. J. Guia, M. van der Woude, \& J. van der Leun (Eds.), Social control and justice: crimmigration in the age of fear. (pp. 177-198). Eleven International Publishing.

Jennissen, R., Engbersen, G., Bokhorst, M., \& Bovens, M. (2018). De nieuwe verscheidenheid. Toenemende diversiteit naar herkomst in Nederland. Wetenschappelijke Raad voor het Regeringsbeleid.

Kanan, J. W., \& Pruitt, M. V. (2002). Modeling fear of crime and perceived victimization risk: The (in) significance of neighborhood integration. Sociological Inquiry, 72(4), 527-548

Kolo, P. (2012). Measuring a new aspect of ethnicity: The appropriate diversity index. Discussion paper No. 221. Goettingen: Ibero-Amerika Institut für Wirtschaftsforschung.

Koopmans, R., \& Schaeffer, M. (2015). Relational diversity and neighbourhood cohesion. Unpacking variety, balance and in-group size. Social Science Research, 53, 162-176

Koopmans, R., \& Schaeffer, M. (2016). Statistical and perceived diversity and their impacts on neighborhood social cohesion in Germany, France and the Netherlands. Social Indicators Research, 125, $853-883$

Laméris, J., Hipp, J. R., \& Tolsma, J. (2018). Perceptions as the crucial link? The mediating role of neighborhood perceptions in the relationship between the neighborhood context and neighborhood cohesion. Social Science Research, 72, 53-68

Lancee, B., \& Dronkers, J. (2011). Ethnic, religious and economic diversity in Dutch neighbourhoods: explaining quality of contact with neighbours, trust in the neighbourhood and inter-ethnic trust. Journal of Ethnic and Migration Studies, 37(4), 597-618

Laurence, J., Schmid, K., \& Hewstone, M. (2018). Ethnic diversity, inter-group attitudes and countervailing pathways of positive and negative inter-group contact: an analysis across workplaces and neighbourhoods. Social Indicators Research, 136, 719-749

Laurence, J., Schmid, K., \& Hewstone, M. (2019). Ethnic diversity, ethnic threat, and social cohesion: (re)-evaluating the role of perceived out-group threat and prejudice in the relationship between community ethnic diversity and intra-community cohesion. Journal of Ethnic and Migration Studies, 45(3), 395-418

Lieberson, S. (1969). Measuring population diversity. American Journal of Sociology, 43(6), 850-862 
Liska, A. E., Sanchirico, A., \& Reed, M. D. (1988). Fear of crime and constrained behavior specifying and estimating a reciprocal effects model. Social Forces, 66(3), 827-837

Liu, E. Y., \& Polson, E. C. (2016). The colors of fear: A multilevel analysis of fear of crime across Houston area neighborhoods. Journal of Ethnicity in Criminal Justice, 14(4), 307-326

Maas, C. J. M., \& Hox, J. J. (2005). Sufficient sample sizes for multilevel modeling. Methodology, 1(3), 86-92

McPherson, M., Smith-Lovin, L., \& Cook, J. M. (2001). Birds of a feather: homophily in social networks. Annual Review of Sociology, 71(1), 415-444

Merry, S. E. (1981). Urban danger: life in a neighborhood of strangers. Temple University Press.

Moeller, G. L. (1989). Fear of criminal victimization: The effect of neighborhood racial composition. Sociological Inquiry, 59(2), 208-221

Morenoff, J. D., Sampson, R. J., \& Raudenbush, S. W. (2001). Neighborhood inequality, collective efficacy, and the spatial dynamics of urban violence. Criminology, 39(3), 517-558

Pickett, J. T., Chiricos, T., Golden, K. M., \& Gertz, M. (2012). Reconsidering the relationship between perceived neighborhood racial composition and whites' perceptions of victimization risk: Do racial stereotypes matter? Criminology, 50(1), 145-186

Preacher, K. J., Zhang, Z., \& Zyphur, J. (2011). Alternative methods for assessing mediation in multilevel data: the advantages of multilevel SEM. Structural Equation Modeling, 18(2), 161-182

Preacher, K. J., Zyphur, M. J., \& Zhang, Z. (2010). A general multilevel SEM framework for assessing multilevel mediation. Psychological Methods, 15(3), 209-233

Putnam, R. D. (2007). E Pluribus Unum: Diversity and community in the twenty-first century The 2006 Johan Skytte prize lecture. Scandinavian Political Studies, 30(2), 137-174

Quillian, L. (1995). Prejudice as a response to perceived group threat: Population composition and antiimmigrant and racial prejudice in Europe. American Sociological Review, 60(4), 586-611

Quillian, L., \& Pager, D. (2001). Black neighbors, higher crime? the role of racial stereotypes in evaluations of neighborhood crime. American Journal of Sociology, 107(3), 717-767

Reynal-Quarol, M. (2002). Ethnicity, political systems, and civil wars. Journal of Conflict Resolution, 46(1), 29-54

Riger, S., LeBailly, R. K., \& Gordon, M. T. (1981). Community ties and urbanites' fear of crime: An ecological investigation. American Journal of Community Psychology, 9(6), 653-665

Rountree, P. W., \& Land, K. C. (1996). Perceived risk versus fear of crime: Empirical evidence of conceptually distinct reactions in survey data. Social Forces, 74(4), 1353-1376

Sampson, R. J., Raudenbush, S. W., \& Earls, F. (1997). Neighborhoods and violent crime: A multilevel study of collective efficacy. Science, 277(5328), 918-924

Scarborough, B. K., Like-Haislip, T. Z., Novak, K. J., Lucas, W. L., \& Alarid, L. F. (2010). Assessing the relationship between individual characteristics, neighborhood context, and fear of crime. Journal of Criminal Justice, 38(4), 819-826

Schaeffer, M. (2013). Can competing diversity indices inform us about why ethnic diversity erodes social cohesion? A test of five diversity indices in Germany. Social Science Research, 42(3), 755-774

Schlueter, E., \& Scheepers, P. (2010). The relationship between outgroup size and anti-outgroup attitudes: A theoretical synthesis and empirical test of group threat- and intergroup contact theory. Social Science Research, 39(2), 285-295

Skogan, W. G. (1999). Measuring What Matters: Crime, Disorder, and Fear. Measuring what matters: Proceedings from the policing research institute meetings. (pp. 37-53). National Institute of Justice and Office of Community Oriented Policing Services.

Sluiter, R., Tolsma, J., \& Scheepers, P. (2015). At which geographic scale does ethnic diversity affect intraneighborhood social capital? Social Science Research, 54, 80-95

Tolsma, J., \& van der Meer, T. (2017). Losing wallets, retaining trust? the relationship between ethnic heterogeneity and trusting coethnic and non-coethnic neighbours and non-neighbours to return a lost wallet. Social Indicators Research, 131, 631-658

Tolsma, J., van der Meer, T., \& Gesthuizen, M. (2009). The impact of neighbourhood and municipality characteristics on social cohesion in the Netherlands. Acta Politica, 44(3):286:313

Uslaner, E. M. (2011). Trust, diversity, and segregation in the United States and the United Kingdom. Comparative Sociology, 10(2), 221-247

van der Meer, T., \& Tolsma, J. (2014). Ethnic diversity and its effects on social cohesion. Annual Review of Sociology, 40(1), 459-478

Vertovec, S. (2007). Super-diversity and its implications. Ethnic and Racial Studies, 30(6), 1024-1054

Vervoort, M. (2012). Ethnic concentration in the neighbourhood and ethnic minorities' social integration: weak and strong social ties examined. Urban Studies, 49(4), 897-915 
Vervoort, M., Flap, H., \& Dagevos, J. (2011). The ethnic composition of the neighbourhood and ethnic minorities' social contacts: Three unresolved issues. European Sociological Review, 27(5), 586-605

Yuan, Y., \& McNeeley, S. (2016). Social ties, collective efficacy, and crime-specific fear in seattle neighborhoods. Victims and Offenders, 12(1), 90-112

Publisher's Note Springer Nature remains neutral with regard to jurisdictional claims in published maps and institutional affiliations. 